\title{
Choice of Food: Preventive Measure during Covid-19 Outbreak
}

Archana Bhatta

Author Info:

Central Campus of

Technology, Hattisar, Dharan

\section{Corresponding Author:}

Ms. Archana Bhatta archanabhatta529@gmail.com

\section{ABSTRACT}

As the COVID-19 pandemic has affected communities around the globe, people are facing the fear of being infected by it. It is believed that coronavirus disease 2019 is directly associated with an individual's immune response, with no documented research evidence found yet. But, Covid-19 is genetically similar to Severe Acute Respiratory Syndrome Coronavirus (SARS-CoV), therefore the same immune response is expected for COVID-19. It has also been found that individuals having weaker immune functions are more suspected to infect and have a high fatality rate. Preventive measures such as good personal hygiene, wearing the mask, avoiding crowded places and sick individuals, practicing quarantine and proper choice of food can help an individual to be safe from the risk of current COVID-19 infection. Research findings state that nutrition influences immune strength thereby protecting our body from the attack of pathogens. Increasing the intake of a nutritious diet can help to enhance the immune system and makes an individual less susceptible to diseases, which is also considered as a key factor for the prevention of viral infection like COVID-19. Therefore, the incorporation of foods rich in nutrients that boosts our immunity is one of the possible essential preventive measures to fight with this global crisis.

Keywords: COVID-19, Pandemic, Immune system, Nutrients

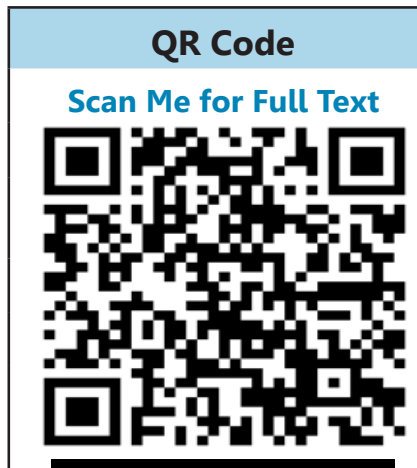

(ه) View PDF

\section{Article Info}

Received:2 April 2020; Accepted: 8 May 2020; Published Online: 10 May 2020

How to cite this article in Vancouver Style?

Bhatta A. Choice of Food: Preventive Measure during Covid-19 Outbreak. Europasian J Med Sci. 2020;2(1):85-89. https://doi.org/10.46405/ejms.v2i1.49

Conflict of Interest: None Declared;

\section{Disclaimer}

Source of Support: Nil

Copyright: $(2020$ by author(s). This is an open access article distributed under the terms of the Creative Commons Attribution International License 4.0 @- o which permits unrestricted use, distribution, and reproduction in any medium, provided the original work is properly cited.

\section{Publisher's Note}

The Europasian Journal of Medical Sciences (EJMS) is an official Journal of Nirvana Psychosocial Care Center \& Research Institute (www. nirvanapscc.com) and published by it. The Journal as well as publisher remain neutral with regards to any jurisdictional claims in any published articles, its contents and the institutional affiliations of the author(s). 


\section{INTRODUCTION}

As the COVID-19 pandemic has affected communities around the globe, people are facing the fear of being infected by it. It is believed that coronavirus disease 2019 is directly associated with an individual's immune response, with no documented research evidence found yet. But, Covid-19 is genetically similar to Severe Acute Respiratory Syndrome Coronavirus (SARS-CoV), therefore the same immune response is expected for COVID-19. ${ }^{1}$ It has also been found that individuals having weaker immune functions are more suspected to infect and have a high fatality rate. ${ }^{2}$ Preventive measures such as good personal hygiene, wearing the mask, avoiding crowded places and sick individuals, practicing quarantine and proper choice of food can help an individual to be safe from the risk of current COVID-19 infection. Research findings state that nutrition influences immune strength thereby protecting our body from the attack of pathogens. ${ }^{3}$

Covid-19 first identified in Wuhan, China, in December 2019, and recognized as a pandemic on March 11, 2020, by World Health Organization (WHO) is leading to global panic. ${ }^{4}$ Its infection is spreading among more than 215 countries and territories ${ }^{5}$. Until the end of April, it has affected approximately three million people, with the death toll of almost 210,000 people worldwide, and increasing rapidly like a wildfire. So, this novel coronavirus of 2020 has become a new terror recently. In Nepal, the first case of coronavirus was reported in Kathmandu on 24 January 2020 and on $26^{\text {th }}$ April 2020, total cases of coronavirus increased up to 52 people and 16 people had recovered. ${ }^{6}$ Various health agencies and researchers worldwide are working together to carry out multiple clinical

trials to halt the virus infection that has threatened the lives of human beings. Unfortunately, no specific vaccines or antiviral treatment has been approved. Millions of infected people with this new spread disease have to rely on their immune system to defend off the virus. Research findings confirm the significance of adequate and appropriate nutrients for the proper functioning of the cells in the immune system. ${ }^{7}$ These nutrients improve resistance to infection by restoring immune function. This is the reason why we should be aware of the nutrients during this time of the global pandemic. Proper diet and avoiding processed junk food is required for maintaining a good health condition. Make fresh fruits and vegetables the focus of your diet if possible and adequate intake of foods rich in zinc, magnesium, iron and Vitamins A, E, B6 and B12 are responsible to support immune function. ${ }^{8}$ Fruits and vegetables like spinach, carrots, peaches, etc, that contain the highest micronutrients are especially recommended. Due to this outbreak and strict lockdown, the lives of people have been upended as they are compelled to stay in their house. During this time of lockdown, it is prescribed to focus on lifestyle management and stress reduction that also supports the immune system.

\section{COVID-19 and Immune system}

An immune response is the main impediment that plays a vital role in protecting against infectious agents. Both the innate immunity and adaptive immunity are strongly associated with increased susceptibility to infections ${ }^{9}$. When a pathogen invades the host, then the immune system starts to defend the invaders. The key role of the immune system is to protect our body or tackle against pathogens. The susceptibility of being diseased depends upon the effectiveness of the immune response. Therefore, lower immunity results in decreased ability to fight against the pathogen and becomes more prone to diseases. On the contrary, the suppressed immune system causes delayed antibody response making the body of an individual more susceptible to the attack of virus ${ }^{10}$. Likewise, until the vaccine for COVID-19 is available, the human immune system needs to adapt unaided to this current deadly threat. Most coronavirus-related deaths are not due to damage caused by the virus rather it is by the suppressed immune system of the human body that failed to fight against it. If a high quantity of viral particles infects the human body, the virus is more likely to replicate and spread rapidly before the human immune system response. At this point, the immune system can freak out and even can cause substantial cell death, resulting in most severe infections and acute respiratory distress syndrome.

Although all age groups are at risk of contracting COVID-19, older people face a significant risk of developing severe illness due to the suppressed immune system as well as doctors and nurses can have more severe infections due to exposure to huge amounts of the virus during caring of patients. ${ }^{11}$ Apart from this, some people who are immunosuppressed due to other illnesses like diabetes, heart and lung diseases are the most affected populations during this current time 
of crisis. According to a new study based on the COVID-19 pandemic, the mortality rate among the infected cases increases with increases in age, i.e; $0.06 \%$ for an age of $20 \mathrm{~s}, 8.6 \%$ for an age of $70 \mathrm{~s}$, $13.4 \%$ for an age of 80 s. $^{12}$

\section{Food and Nutrition Tips during COVID-19 pandemic}

A nutritious balanced diet is essential to keep us healthy. Adequate nutrition is required for all the cells to function properly and to support immune cells to initiate responses against pathogens. The performance of the immune system is influenced by what we eat. A healthy balanced diet by incorporation of specific foods can boost our immunity that can be a key to lower the risk of infection..$^{13}$ As the human immune system needs to fight back to the possible viral infection, so, it is important to be more mindful of taking the food that enhances our immunity. Food rich in nutrients such as magnesium, copper, folate, iron, zinc and vitamins A, B6, B12, C and D plays a crucial role in the normal immune system. Magnesium helps in delivering oxygen from our lungs to the entire human body, which is quite essential during Covid-19 infection as the virus attacks the respiratory tract. ${ }^{14}$ Maintaining proper immune function is good but boosting our immune system may be more essential during the times of increased risk, like now. Some healthy foods which can boost the immune system of the human body are as follows:

\section{Turmeric}

Turmeric, a widely used Nepali spice is considered to boost immunity. Research suggests that it contains a bright-yellow compound known as curcumin, that has antioxidant and anti-inflammatory effects ${ }^{15}$, which enhances immune function.

\section{Broccoli}

Broccoli is rich in Vitamin A, C, and E. Broccoli contains antioxidants such as sulforaphane and phytochemicals that can fight against viruses and support the immune system. It can be a good choice to eat regularly if it is available during this time of lockdown.

\section{Spinach}

Spinach is one of the easy to grow vegetables. We can easily get it, even during this time of lockdown. Spinach has beta-carotene, i.e; the main dietary source of Vitamin A that increases the disease-fighting cells in the body. It is also rich in vitamin $\mathrm{C}$ and full of antioxidants and nutrients like flavonoids, carotenoids, etc. that helps in proper immune function. ${ }^{16}$

\section{Strawberries}

Strawberries, as it is rich in Vitamin $C$ and bioactive phytochemicals, helps in strengthening the immune system by protecting cells from damage caused by free radicals. ${ }^{17}$ However, it may not be easily available during this time of lockdown.

\section{Sunflower seeds}

Sunflower is one of the widely used ornamental plants. Its seed is incredibly rich in phosphorus, magnesium, copper, calcium, iron, phosphorus, selenium and vitamin $E$, which can boost the immune system by fighting off free radicals that can damage cells. ${ }^{18}$ You may have dried sunflower seeds in your kitchen. Remind yourselves to intake more of it.

\section{Garlic}

Garlic, a popular and herb with a characteristic aroma, is rich in sulfur-containing compounds. It helps to boost the immune system and can fight against common cold and infections. It is widely believed to have antiviral and antibacterial effects, with health benefits such as reducing the risk of heart disease and lowering blood pressure.

\section{Almond}

Almond is popular among dried foods. It is an excellent source of Vitamin $E$ and antioxidants that protect against oxidative stress. They also contain manganese, fiber and helps to reduce cholesterol levels. Also, almonds are rich in magnesium that helps to strengthen our immune system's natural killer cells and lymphocytes. Check how often you are taking it during the lockdown.

\section{Lemon/Orange/Kiwi}

Lemon is a rich source of Vitamin C. However, no scientific document has been found that lemon can cure disease. But, drinking warm water with lemon slices helps the immune cells to work properly. Further, kiwi contains more Vitamin $\mathrm{C}$ that is almost twice of lemons and oranges. Kiwi contains many minerals and vitamins such as Vitamin A, B6, B12, E and potassium, calcium, iron as well as folate, which gives our body a nutritional boost. Vitamin $C$ acts as a prooxidant for immune cells and strengthens the immune system against harmful pathogens. ${ }^{19} \mathrm{It}$ may not be the season for orange now but check if lemon or kiwi are available. 


\section{Mushrooms}

Mushroom as a source of Vitamin D, protect us against respiratory diseases which is very significant at the time of the COVID-19 outbreak. Research states Vitamin D supplementation in our diet can lower the risk for infections like respiratory tract infections by reducing the production of proinflammatory compounds in body. ${ }^{20}$

\section{Yogurt}

Yogurt is a great source of probiotics, and Vitamin D is a commonly used dessert in every household. Studies revealed that probiotics can decrease the risk of respiratory infections and also influence immune function. Therefore, yogurt can be beneficial for fighting the common cold and influenza-like respiratory infections and boost our body's natural defenses against diseases.

\section{Papaya}

Papaya is rich in Vitamin B, C, potassium and folate that boost our immune system. It has a digestive enzyme called papain that has anti-inflammatory effects. It can be grown easily in a small space.

\section{KEY MESSAGE}

The impact of COVID-19 has become one of the global heightening concern. While there are no magical foods or any vaccines that protect against COVID-19, so only protective measures can be executed to slow down the risk of spreading this viral infection. ${ }^{22}$ The effectiveness of immune function plays a great role in fighting against the pathogens. Proper immune function depends on the foods that we intake. It may not sound practical to increase the intake of all the foods that have been listed but it is important to be aware of taking food that enhances immunity. Similarly, avoiding sweets, sugar-sweetened beverages, and foods rich in saturated fats, limit intake of processed foods/ red meats, avoid excessive use of drugs, cigarettes, alcohol, etc, could be the right choice during the lockdown. Researches also confirm restful sleep of at least 8 hours, staying hydrated helps to reduce the risk of viral infections. ${ }^{21}$ Further, exercise helps to raise the level of antibodies and white blood cells in the body that fight against infections. ${ }^{22}$ Therefore, engaging in exercises/yoga/meditation and staying active during the time of lockdown is highly recommended. Following the preventive measure is not the only solution, the appearance of alarming symptoms that suspects Covid-19, asks for further consultation as soon as possible.

\section{REFERENCES}

1. Lu R, Zhao X, Li J, Niu P, Yang B, Wu H, Wang W, Song $\mathrm{H}$, Huang B, Zhu N, Bi Y. Genomic characterization and epidemiology of 2019 novel coronavirus: implications for virus origins and receptor binding. The Lancet. 2020 Feb 22;395 (10224):565-74. https:// doi.org/10.1016/S0140-6736(20)30251-8

2. Qin C, Zhou L, Hu Z, Zhang S, Yang S, Tao Y, Xie C, Ma K, Shang K, Wang W, Tian DS. Dysregulation of immune response in patients with COVID-19 in Wuhan, China. Clinical Infectious Diseases. 2020 Mar 12. https://doi.org/10.2139/ssrn.3541136

3. Wimalawansa SJ. global epidemic of coronaviruscovid-19: what can we do to minimize risks. european Journal of Biomedical. 2020;7(3):432-8.

4. Guo YR, Cao QD, Hong ZS, Tan YY, Chen SD, Jin HJ, Tan KS, Wang DY, Yan Y. The origin, transmission and clinical therapies on coronavirus disease 2019 (COVID-19) outbreak-an update on the status. Military Medical Research. 2020;7(1):1-0. https://doi. org/10.1186/s40779-020-00240-0

5. World Health Organization, Coronavirus disease situation report. Accessed from; https://www.who. int/emergencies/diseases/novel-coronavirus-2019

6. Coronavirus(2019-nCoV). Accessed from; https:// www.worldometers.info/coronavirus/country/ nepal.2020. [Link]

7. Childs CE, Calder PC, Miles EA. Diet and Immune Function. 2019;11(8); 1933 https://doi.org/10.3390/ $\underline{\text { nu11081933 }}$

8. Boone HA, Čustović A, Hotić S, Latinović D, Sijerčić A. How to Fight COVID-19 Using a Healthy Lifestyle Approach.2020.

9. Janeway Jr CA. How the immune system protects the host from infection. Microbes and infection. 2001 Nov 1;3(13):1167-71. https://doi.org/10.1016/ S1286-4579(01)01477-0

10. Li G, Fan Y, Lai Y, Han T, Li Z, Zhou P, Pan P, Wang W, Hu D, Liu X, Zhang Q. Coronavirus infections and immune responses. Journal of medical virology. 2020 ;92(4):424-32. https://doi.org/10.1002/jmv.25685

11. Mclntosh K. Coronavirus disease 2019 (COVID-19). Edited by Martin S. Hirsch. UpToDate, https://www. uptodate.Com/contents/coronavirus-disease-2019covid-19. 2020. [Link]

12. D'Souza R, Banerjee A. An Insight into Coronavirus: A Global Pandemic of the 21 st Century.2020.

13. Lopez-Varela S, Gonzalez-Gross M, Marcos A. Functional foods and the immune system: a review. European Journal of Clinical Nutrition. 2002;56(3):S29-33.https://doi.org/10.1038/ sj.ejcn. 1601481

14. Sanderson S. Immune System Defence with Vitamin 
C and Magnesium.2020.

15. Hewlings SJ, Douglas S. Kalman. Curcumin: A Review of Its' Effects on Human Health." Foods. 2017;6:1092. https://doi.org/10.3390/foods6100092

16. Somerville VS, Braakhuis AJ, Hopkins WG. Effect of flavonoids on upper respiratory tract infections and immune function: A systematic review and metaanalysis. Advances in nutrition. 2016 May;7(3):48897. https://doi.org/10.3945/an.115.010538

17. Törrönen $R$, Määttä K. Bioactive substances and health benefits of strawberries. InIV International Strawberry Symposium. 2000; 567:797-803). https:// doi.org/10.17660/ActaHortic.2002.567.176

18. Nandha R, Singh H, Garg K, Rani S. Therapeutic potential of sunflower seeds: An overview. IJRDPL. 2014; 3:0.
19. Erol A. High-dose intravenous vitamin $C$ treatment for COVID-19.2020. https://doi.org/10.31219/osf.io/ p7ex8

20. Cheung $P C$, editor. Mushrooms as functional foods. John Wiley \& Sons; 2008 Dec 29. https://doi. org/10.1002/9780470367285

21. Amersbach G. Coronavirus and the Importance of a Strong Immune System. Mar 11,2020. https://doi. org/10.22207/JPAM.14.SPL1.31

22. Asmita Priyadarshini Khatiwada and Sunil Shrestha, Pharmacy Patronage: Identifying the Roles of Nepalese Pharmacists in Tacking COVID-19, J. Pure Appl. Microbiol., May 2020; 14(Spl Edn.).

23. Join IFM, Calendar P. Boosting Immunity: Functional Medicine Tips on Prevention \& Immunity Boosting During the COVID-19 (Coronavirus) Outbreak.2020. 